\title{
MODIFIED DUAL-STAGE INVERTER APPLIED IN A THREE-PHASE GRID- CONNECTED PV SYSTEM USING BEHAVIOR MATCHING TECHNIQUE
}

\author{
Marcio M. Casaro, Lenon Schmitz, Carolina Knaesel, Denizar Cruz Martins \\ Federal University of Santa Catarina \\ Department of Electrical Engineering - Power Electronics Institute \\ P. O. Box 5119, Zip Code: 88040-970 - Florianopolis, SC - Brazil \\ denizar@inep.ufsc.br
}

\begin{abstract}
This paper presents a grid-connected PV system in a centralized configuration and constructed through a three-phase dual-stage inverter. In this topology, usually, a DC-DC converter performs the maximum power point tracking (MPPT) and an inverter is responsible for controlling the grid-current. For the DC-DC stage the three-phase series resonant converter (SRC3) is chosen thanks to the advantages that it exhibits. However, it is inadequate for the accomplishment of MPPT, due to its efficiency strongly dependent on the implemented deadtime and switching frequency. Then, this paper proposes a conceptual modification, i.e., a modified dual-stage inverter in which the inverter stage is responsible for both the MPPT and the grid-current control. In addition, the DC-DC converter operates with constant duty cycle and frequency. Such configuration requires a new concept, introduced as Behavior Matching. It serves as a fundamental feature for the DC-DC converter to reproduce the $P V$ array $I-V$ characteristic when they are connected, without control action. The maximum power operating point (MPOP) is found by maximizing the direct axis current, obtained by Park's transformation from the inverter, through the perturbation and observation algorithm (P\&O). Any specific measurement to realize MPPT is not needed. The galvanic isolation is achieved by using a high-frequency transformer. The structure is appropriate for high power applications, above $10 \mathrm{~kW}$.
\end{abstract}

Keywords - Grid-Connected PV System, Dual-Stage Inverter, MPPT, Behavior Matching.

\section{INTRODUCTION}

The photovoltaic solar energy represents an emergent technology in function of the continuous fall in the production costs and in the technological progress of the PV modules. This alternative energy can significantly contribute with the reduction in the emission of greenhouse gases in the atmosphere, which attack the environment deeply.

Around $75 \%$ of the PV systems installed in the world are grid-connected [1]. In the grid-connected PV system DC-AC converters (inverters) are need to realized the grid interconnection, inverting the dc current that comes from the PV array into a sinusoidal waveform synchronized with the

Manuscript received on 26/10/2012; revised on 15/01/2013 and recommended by Regular Section Editor, Henrique A. C. Braga, on $22 / 02 / 2013$ utility grid. Besides, the DC-AC converter is used to stabilize the dc-bus voltage to a specific value, because the output voltage of the PV array varies with temperature, irradiance, and the effect of MPPT (maximum power point tracking) [2, $3-5,6,7]$. The DC-AC conversion systems, depending on its topology, can be classified as presented in $[8,9]$.

Reference [10] presents four configurations commercially acceptable showing how the PV modules are connected with inverters and these are connected with the power grid.

The high efficiency is one of the most important characteristics of a PV inverter. Thus, whenever possible, these inverters are nonisolated electronic circuits, since a transformer imposes an efficiency drop. This efficiency drop is $2 \%$ larger for a low than for a high-frequency transformer [1]. Hence, when grid-isolation is mandatory, the incorporation of a high-frequency transformer is a trend. This implies the need for a DC-DC converter in the structure of the PV power system. The isolated ZVS Full-Bridge DC-DC converter is usually used at power levels above $750 \mathrm{~W}$ [8], to perform both the MPPT and the galvanic isolation. Commonly, its efficiency ranges from $92 \%$ to $93 \%$ under a $45 \%$ to $100 \%$ load condition [4]. This performance is not recommended for high power industrial applications. With nonisolated versions, the efficiency can be increased from $96 \%$ to $98 \%$ [11].

As an alternative to Full-Bridge based converters the three-phase conversion has some advantages, such as [12]:

- Reduced switching stresses of the power semiconductor devices.

- $\quad$ Reduced size and ratings of associated reactive components.

- Better transformer copper and core utilization.

As important as high efficiency, it is the inverter cost. Reference [8] indicates the centralization of inverter (Central-plant inverter) for reducing cost.

Considering reducing the volume and weight of the whole system, a dual-stage inverter configured in a central-plant [9] is proposed in this paper; however, with two basic differences:

1) Uses a three-phase DC-DC converter in place of a singlephase. In [12] it is demonstrated that the three-phase conversion has some advantages such as:

- High-frequency transformer reduction in comparison to the transformer used in a Full-Bridge DC-DC converter, operating with the same switching frequency.

- Increase of three times in the input and output current frequencies, reducing the size of the filters components.

- Better distribution of the losses. 
The three-phase isolated DC-DC series resonant converter (SRC3) $[13,14]$ was applied to act as DC-DC stage. Despite the galvanic isolation, the measured efficiency of the DC-DC stage was limited to $96 \%$ to $97.5 \%$ under a $45 \%$ to $100 \%$ load condition.

2) The MPPT will not be carried out by DC-DC stage; it will be performed by the inverter, which is also responsible for the grid-current control. It is important to emphasize that any measurements of voltage or current in the photovoltaic array are not made. It is an indirect MPPT, possible due to the behavior matching between the DC-DC converter output I-V characteristic and the PV array I-V characteristic, when they are connected. Then, behavior matching serves as fundamental feature for DC-DC converters to reproduce the PV array I-V characteristic without control action. References [15, 16 and 17$]$ indicate this possibility.

The traditional dual-stage inverter implements some control strategy in the DC-DC stage. In this paper a conceptual modification is proposed that is called Modified Dual-Stage Inverter $[18,19]$. In this new approach there is no control in the DC-DC stage, the SRC3 operates with constant frequency and duty-cycle, representing a very high efficiency operation. All the control, MPPT and grid-current, are implemented in the DC-AC stage (inverter) that consists of a three-phase bidirectional power flow PWM voltage source inverter (VSI3). This is the principal power electronics circuit of a Three-Phase Grid-Connected PV Power System. Figure 1 shows the basic idea of a modified dual-stage inverter.

The DC-AC stage performs the MPPT through the P\&O method $[4,6,20]$ to maximize the direct axis current, $I_{d}$, required for the grid current control. The current $I_{d}$ reflects the active power delivered by the photovoltaic array and is expressed through the inverter modeling, using the Park transformation [21]. Then, the inverter output power is maximized without additional sensors. In a single-stage inverter, this principle can also be used. Figure 2 presents the proposal topology for the dual-stage inverter in a three-phase configuration.

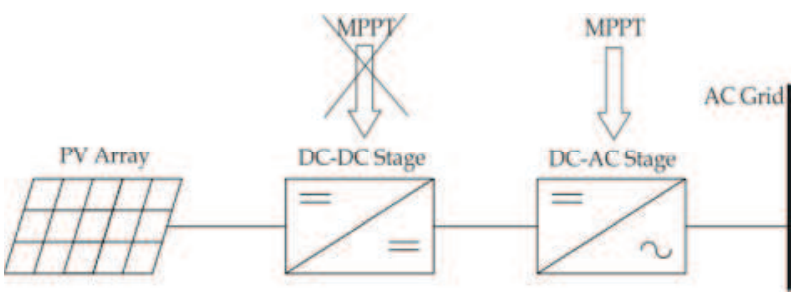

Fig. 1. Modified dual-stage inverter.

\section{DUAL-STAGE INVERTER}

It is desired the system to be suitable for high power applications, above $10 \mathrm{~kW}$. Thus, the two stages of the inverter are three-phase configurations.

\section{A. DC-DC Stage}

When the single-phase DC-DC converter is replaced by a three-phase one, several advantages appear [12]:

- Faster response times;

- Low stresses on active devices;

- Filters components reduction;

- High-frequency transformer reduction.

Amongst the three-phase DC-DC converters, most attractive are those that present soft commutation. This characteristic is important due to be high switching frequency in which they can operate, keeping the high efficiency and the heat sinks size in reasonable levels. In addition, with the rise of the switching frequency, becomes a significant reduction in the transformer size and weight.

Various three-phase DC-DC converters with soft commutation are available $[13,14,22,23]$. Each of them was evaluated about the efficiency in different input power levels, components number, EMI emission, performance under unbalanced conditions and power range. The topology that appears to relate the best characteristics for the proposal application in this paper is presented in Figure 3, obtained from [14]. The transformer was replaced by their leakage inductances, $L d$.

The switches are gated by 6 phase-shifted signals. Neglecting the deadtime between two switches in each inverter leg, all switches are turned on exactly half a period.

When the switching frequency, $f_{S}$, is equal to resonance frequency, $f r$, the converter operates in ZCS. If $f_{s}>f r$, the converter operates in ZVS. In this condition, the efficiency is much reduced for low-power transfer [14]. Then:

$$
\begin{gathered}
f_{S}=f r=\frac{1}{2 \cdot \pi \cdot \sqrt{L d \cdot C r}} \\
\text { Iin }=I p v=\frac{6}{\pi^{2} \cdot R_{\text {loss }}}\left(\text { Vin }-V_{d c}{ }^{\prime}\right)
\end{gathered}
$$

where:

- Iin - average input current;

- Ipv - PV array current;

- $V_{d c}{ }^{\prime}$ - average output voltage of the three-phase bridge rectifier, referred to the primary side;

- Vin - average DC-DC converter input voltage;

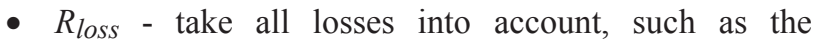
conduction and switching losses of the switches and

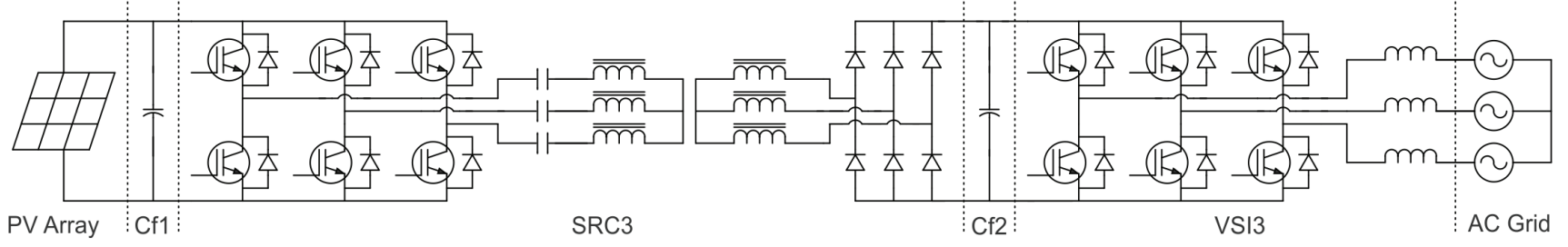

Fig. 2. Three-Phase dual-stage inverter in centralized configuration. 
diodes, the dielectric losses of the capacitors, the copper and iron losses of the three-phase transformer and the conduction losses of wires and connections;

- $\quad L d$ - leakage inductance of the transformer;

- $\mathrm{Cr}$ - resonant capacitor.

The transformer turn's ratio can be defined by (3).

$$
n=\frac{N_{2}}{N_{1}}
$$

where:

- $N_{1}$ - number of turns on the transformer primary winding;

- $N_{2}$ - number of turns on the transformer secondary winding.

From (2) and (3), (4) and (5) can be found.

$$
\begin{aligned}
& R_{\text {loss }}=\frac{6}{\pi^{2} \cdot \operatorname{Iin}}\left(\operatorname{Vin}-\frac{V_{d c}}{n}\right) \\
& \operatorname{Vin}=\frac{\pi^{2}}{6} \cdot R_{\text {loss }} \cdot \operatorname{Iin}+\frac{V_{d c}}{n}
\end{aligned}
$$

A peculiarity about this converter is that, despite the many advantages that it presents, it is inadequate for the accomplishment of MPPT, due that its efficiency extremely depends on the implemented deadtime and switching frequency [14]. These variables should not vary. That deficiency can be neglected thanks to the Behavior Matching $[16,17,18,19,24]$.

\section{B. DC-AC Stage}

Two new trends for this stage are discussed in [25] and [26], using LCL filters on a grid interface and replacing the conventional three-level PWM inverter by a multilevel inverter. The objectives are the same: lower total harmonic distortion (THD) and more compact designs. However, for the application presented in this paper, the three-phase current-controlled voltage-source inverter with $L$ filter is adequate.

The inverters used for grid interfacing are broadly classified as voltage-source inverters (VSI) and currentsource inverters (CSI). The control schemes can be classified as current-controlled inverters (CCI) and voltage-controlled inverters (VCI).

PV solar arrays are fairly good approximation to a current source. Then, most PV inverters are voltage source. In addition, with vector modulation, the THD measured is insignificant when harmonics below the switching frequency are considered.

The current-controlled scheme objective is to control active and reactive components of the current fed into the grid. The current controllers are better suited for the control of power export from PV inverters to the utility grid since they are less sensitive to errors in synchronizing sinusoidal voltage waveforms.

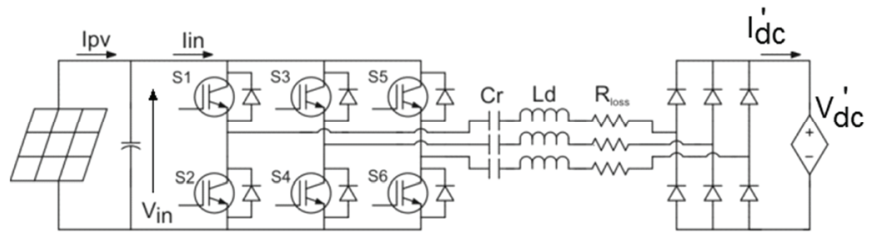

Fig. 3. DC-DC three-phase series resonant converter (SRC3).
The structure of the three-phase current-controlled voltage-source inverter is shown in the Figure 4.

Performing a Park's transformation, its dynamical model in the dq-frame can be described by (6).

$$
\begin{aligned}
& \frac{d I_{d}}{d t}=\frac{V_{d}}{L}+\omega \cdot I_{q}-\frac{R}{L} \cdot I_{d}-\frac{V_{d c}}{L} \cdot D_{d} \\
& \frac{d I_{q}}{d t}=-\omega \cdot I_{d}-\frac{R}{L} \cdot I_{q}-\frac{V_{d c}}{L} \cdot D_{q} \\
& \frac{d V_{d c}}{d t}=-\frac{I_{d c}}{C f 2}+\frac{I_{d}}{C f 2} \cdot D_{d}+\frac{I_{q}}{C f 2} \cdot D_{q}
\end{aligned}
$$

where:

- $I_{d}, I_{q}, V_{d c}-$ state variable;

- $D_{d}, D_{q}$ - control variables;

- $L=L_{1}=L_{2}=L_{3}$

- $R=R_{1}=R_{2}=R_{3}$ - intrinsic resistance of the inductance $L_{1}, L_{2}, L_{3}$, respectively;

- $\quad V_{d}, \omega$ - utility grid parameters $\left(V_{d}=\sqrt{3} \cdot V_{g}\right.$, and $V_{g}$ is the grid rms phase voltage, and $\omega=2 \pi f$, where $f$ is the grid frequency);

- $I_{d c}$ - average output current of the three-phase bridge rectifier, i.e., the average input current of the threephase VSI.

Since $P_{g}=V_{d} \times I_{d}$ represents the power that the inverter injects in the grid, the MPPT can be performed perturbing $V_{d c}$ and observing $I_{d}$, according (7).

$$
\begin{gathered}
V_{d c}(k+1)=V_{d c}(k)+ \\
+\Delta V \cdot \operatorname{sign}\left[V_{d c}(k)-V_{d c}(k-1)\right] \cdot \operatorname{sign}\left[I_{d}(k)-I_{d}(k-1)\right]
\end{gathered}
$$

Setting $V_{d c}$, the DC-AC stage defines the input characteristic behavior of the DC-DC converter, whose determines the PV array operation point. When $I_{d}$ is maximized, the PV array operates on MPOP. As noted, $I_{d}$ and $V_{d c}$, used by MPPT, are state variables employed in the grid-current control, i.e., additional hardware is not need. The next section explained this behavior in detail, which represents the behavior matching of the proposed dual-stage inverter.

\section{BEHAVIOR MATCHING AND THE MPPT PROPOSAL TECHNIQUE}

The indirect MPPT is a type of tracking that uses the connection between measured variables and the position of the maximum power operating point (MPOP). Some variables, as temperature and open circuit voltage of the PV generator, are used. It is not a true MPPT technique.

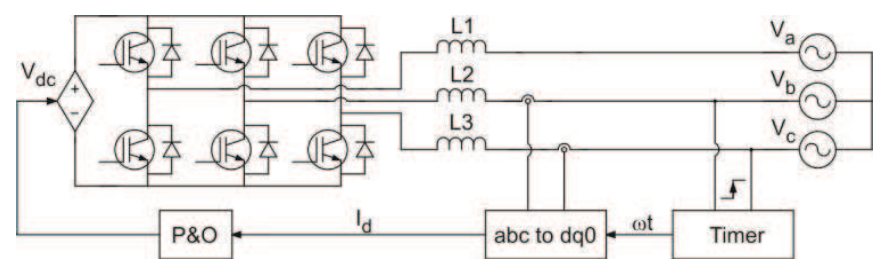

Fig. 4. Three-phase current-controlled VSI. 
The direct MPPT requires, in principle, a measurement of generator voltage and current as well as a multiplication of these variables [27].

In both cases, specific measurements for MPPT are made. In the proposed grid-connected dual-stage inverter the direct axis current, $I_{d}$, is observed, which serves for the inverter stage to set $V_{d c}$. These actions define the input characteristic behavior of the DC-DC converter, which determines the PV array operation point [28]. When $I_{d}$ is maximized, the PV array operates on MPOP. As noted, the variables used in the MPPT are $I_{d}$ and $V_{d c}$, initially employed in the grid current control, i.e., any specific measurement for MPPT's purpose is not made.

The DC-DC converter operates with constants duty-cycle and frequency. It is designed to work with an efficiency of 97\% coupled to the PV array shown in the section II.A, working under Standard Test Conditions - STC (irradiance of $1 \mathrm{~kW} / \mathrm{m}^{2}$, spectrum of 1.5 air mass and cell temperature of $25^{\circ} \mathrm{C}$ ), resulting in $R_{\text {loss }}=0.32 \Omega$ and $V_{d c}{ }^{\prime}=255 \mathrm{~V}$. Thus, the equation (2) results:

$$
\text { Iin }=1.9(\text { Vin }-255)
$$

Equation (8) is drawn in Figure 5. This illustration also demonstrates that when MPPT is put in action by the inverter stage, $V_{d c}$ vary, shifting the DC-DC converter input I-V characteristic.

The Behavior Matching depends on the DC-DC converter input characteristic at an operation point. Several single and three-phase converters exhibit appropriate input characteristic to present Behavior Matching [17, 29]. In the case of SRC3, the input characteristic curve is a straight line with a small inclination.

It is important to register that this inclination favors the MPPT on irradiation variations. If this straight line fall together with the line formed by union of the MPOPs, would not be necessary the intervention of the inverter stage for irradiation variations, just in the temperature variations, when it would vary $V_{d}$ in order to move the straight line for a new position, searching the MPOP. Putting upon the PV array I-V characteristic curves and Figure 5, the approaching between the input characteristic of the DC-DC converter and the MPOPs can be found, as shown in Figure 6 .

The PV array operation point is defined by the crossing of its respective I-V characteristic curve with the DC-DC converter input characteristic curve. Then, $I_{p v}$ and $I_{d c}$ are also defined. Figure 7 presents simulation results where it can be seen that the PV array behavior, represented by its $\mathrm{I}-\mathrm{V}$ characteristic, is reproduced on the DC-DC stage output terminals, represented by $I_{d c} \times V_{d c}$. From the controller point of view, $I_{d c} \times V_{d c}$ is similar to $I_{p v} \times \operatorname{Vin}$. Thus, MPPT task is to extract the maximum power of the DC link, or, to inject the maximum power into the grid. The strategies are different, but the result is the same: both tune the DC-DC stage input I-V characteristic to the PV array MPP.

Therefore, Figure 7 shows that the output of the DC-DC stage has behavior matching that of the output terminals of the PV array.

The Behavior Matching Technique brings significant advantages for the PV system since the DC-DC converter input characteristic curve lies very close to the MPP loci, for all MPPT range. Step-down DC-DC converters, with similar input Buck behavior, are eligible to integrate a modified dual-stage inverter.

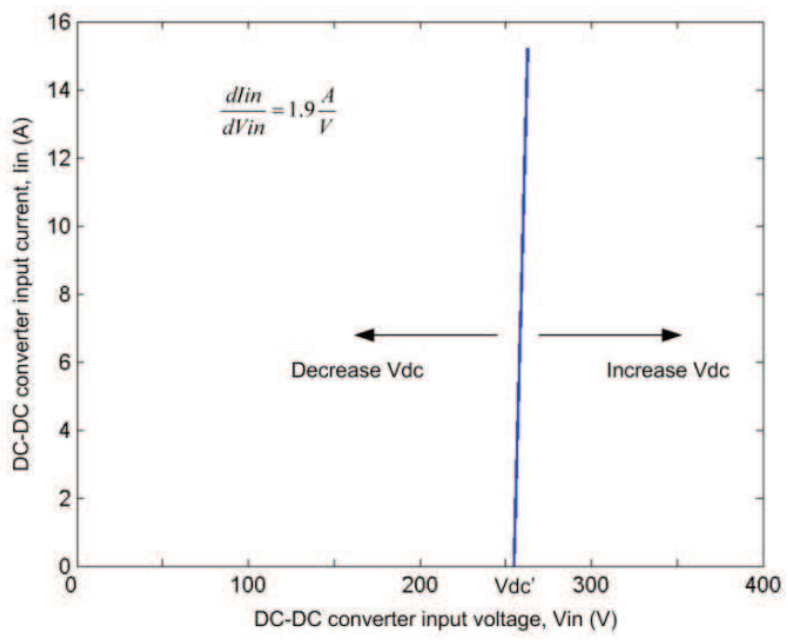

Fig. 5. DC-DC converter input I-V characteristic.

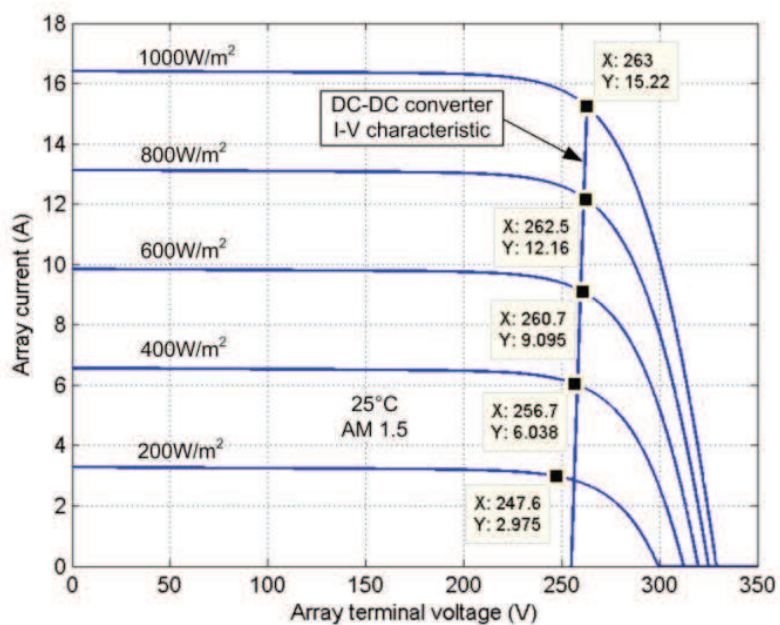

Fig. 6. Crossing between $\mathrm{SRC} 3$ and $4 \mathrm{kWp} \mathrm{PV}$ array I-V characteristic curves.

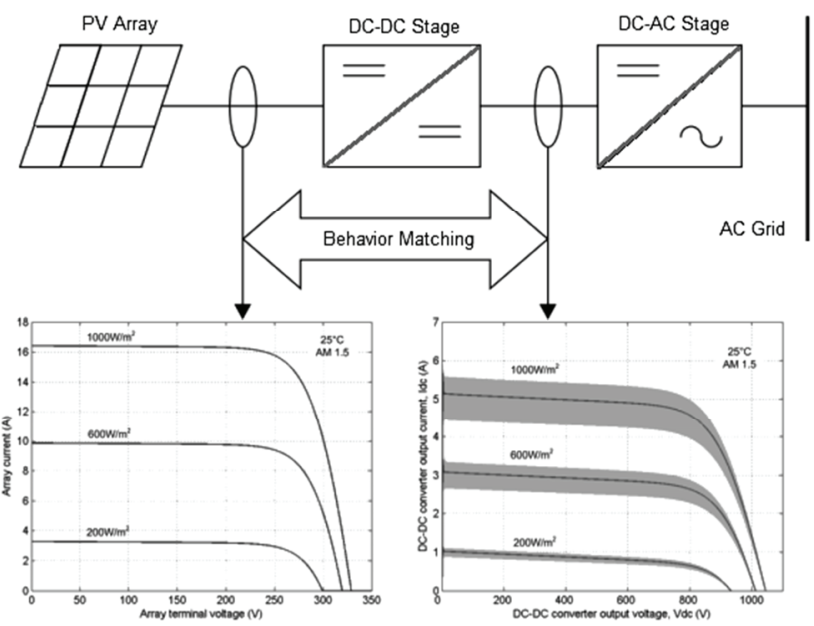

Fig. 7. Behavior matching verifying. 


\section{A. MPPT Proposed Technique Using P\&O Algorithm}

The MPPT proposed technique, using $\mathrm{P} \& \mathrm{O}$ algorithm, has the following procedure:

The temperature and the solar irradiation in the PV array modules vary in different ways. The clouds movement can result in brusque alterations in the irradiance level. However, the temperature tends to vary much more slowly.

The MPOP can be tracked by DC-DC converter through its input characteristic. Since temperature remains constant does not have necessity of the inverter intervention, whose task is to keep the voltage $V_{d c}$ clamped in a reference.

However, periodically, the inverter, through a $\mathrm{P} \& \mathrm{O}$ algorithm, regulates the value of $V_{d c}$ in order to shift the DCDC converter input characteristic, which can be crossing with the array I-V characteristic far from the MPOP due to a temperature variation. Besides $\mathrm{P} \& \mathrm{O}$ others algorithms can also be used.

The topology of the inverter is presented in Figure 4, where $\mathrm{Va}, \mathrm{Vb}$ and $\mathrm{Vc}$ represent the $\mathrm{AC}$ grid phase voltages. It is verified that $\mathrm{P} \& \mathrm{O}$ block is fed by the direct axes current, $I_{d}$, obtained from Park transformation. According to [30], the power that the inverter injects in the grid is given by $P_{g}=V_{d} \times I_{d}$, where $V_{d}$ is constant. Thus, the MPPT can be indirectly performed, perturbing $V_{d}$ and observing $I_{d}$. The $V_{d}$ perturbation at the $(k+1)^{\text {th }}$ sampling is given by (7).

\section{DESIGN EXAMPLE}

The PV array consists of two parallel strings, each with ten KC200GT modules from Kyocera. This PV array defines the nominal input power of the dual-stage inverter, whose value is $P$ in $=4 \mathrm{~kW}$, with $\operatorname{Vin}=263 \mathrm{~V}$ and $\operatorname{Iin}=15.2 \mathrm{~A}$. The estimated efficiency for the DC-DC stage is $\eta_{D C}=97 \%$. Then, the output power of the DC-DC stage is $P_{d c}=3880 \mathrm{~W}$, the same value in the input of the DC-AC stage is obtained. The switching frequencies of the DC-DC and DC-AC stages are $f_{D C}=40 \mathrm{kHz}$ and $f_{A C}=20 \mathrm{kHz}$, respectively. The grid rms phase voltage is $V_{g}=220 \mathrm{~V}$.

\section{A. $P V$ array parallel capacitor $(\mathrm{Cf1})$}

The PV array parallel capacitor is obtained from (9), where $\Delta V$ in is the ripple on the DC-DC stage input voltage. The adopted value is $\Delta$ Vin $=1.0 \% \operatorname{Vin}=2.63 \mathrm{~V}$.

$$
\mathrm{Cf} 1 \geq \frac{\operatorname{Iin}}{215 \cdot f_{D C} \cdot \Delta V \text { in }}=\frac{15.2}{215 \cdot 40 \mathrm{k} \cdot 2.63} \geq 672.03 \mathrm{nF}
$$

A polyester capacitor of $680 \mathrm{nF}$ was used.

\section{B. DC-AC stage input capacitor (Cf2)}

According (10) the input capacitor of the DC-AC stage is obtained. The ripple $\Delta V_{C f 2}$ needs to be a magnitude perturbation's percentage involved in the $\mathrm{P} \& \mathrm{O}$ algorithm. The adopted value was $\Delta V_{C f 2}=0.2 \mathrm{~V}$, while the magnitude perturbation was $4 \mathrm{~V}$.

$$
\begin{aligned}
& \operatorname{Cf} 2 \geq \frac{P_{d c}}{12 \cdot \sqrt{2} \cdot V_{g} \cdot \Delta V_{C f 2} \cdot f_{A C}}= \\
& =\frac{3880}{12 \sqrt{2} \cdot 220 \cdot 0.2 \cdot 20 \mathrm{k}} \geq 259.81 \mu \mathrm{F}
\end{aligned}
$$

The adopted value of Cf2 was $333 \mu \mathrm{F}$, obtained by a series association of three electrolytic capacitors of $1000 \mu \mathrm{F}$.

\section{Grid line inductors $\left(L=L_{1}=L_{2}=L_{3}\right)$}

The grid line inductors are calculated by (12), assuming phase current ripple equal to $\Delta I_{L}=0.42 \mathrm{~A}$. This value corresponds to $5 \%$ of the peak line current, obtained by (11) and is sufficient to keep the THD below $5 \%$.

$$
\begin{gathered}
I_{L p k}=\frac{\sqrt{2} \cdot P_{d c}}{3 \cdot V_{g}}=\frac{\sqrt{2} \cdot 3880}{3 \cdot 220}=8.31 \mathrm{~A} \\
L=\frac{\sqrt{2} \cdot V_{g}}{4 \cdot f_{A C} \cdot \Delta I_{L}}=\frac{\sqrt{2} \cdot 220}{4 \cdot 20 \mathrm{k} \cdot 0.42} \Rightarrow L=9.3 \mathrm{mH}
\end{gathered}
$$

\section{Resonant Capacitor $(\mathrm{Cr})$}

The three-phase transformer is constructed with three single-phase transformers, in wye connection. The turns ratio is define by $n=N_{2} / N_{1}=3.2$. The leakage inductances have been measure to $L d=3.6 \mu \mathrm{H}$. Appling (1), this results in a resonant capacitor of $\mathrm{Cr}=4.4 \mu \mathrm{F}$, for ZCS operation. Polypropylene capacitors were adopted.

\section{E. Average DC-link Voltage Referred to Primary Side $\left(V_{d c}{ }^{\prime}\right)$}

The average DC-link voltage referred to the primary side can be calculated from (13).

$$
V_{d c}{ }^{\prime}=\eta_{D C} \cdot \operatorname{Vin}=0.97 \cdot 263 \Rightarrow V_{d c}{ }^{\prime}=255 \mathrm{~V}
$$

The voltage presented in (13) is raised to $V_{d c}=816 \mathrm{~V}$ by $n=3.2$. This turns ratio keep the DC-link voltage above 600 $\mathrm{V}$ for all MPPT range.

\section{F. Converter Losses Resistance (Rloss $)$}

In nominal conditions, to sinusoidal resonant currents, the losses are found around $R_{\text {loss }}=0.32 \Omega$, according to (4).

\section{G. Main Data of the Laboratory Prototype}

A SK20GD065 Semikron IGBT module was used. The diode bridge was made with six ultra fast recovery rectifiers FFPF05U120S, of $1200 \mathrm{~V}$ and 5 A. A top view of the prototype is depicted in Figure 8.

\section{SIMULATION AND EXPERIMENTAL RESULTS}

The specifications of the whole system are given in section IV.

\section{A. DC-DC Three-Phase Series Resonant Converter (SRC3) Performance}

A compare unit pertained to a peripheral of the Texas TMS320F2812 controller was configured to generate six gate pulses for SRC3, with duty cycle of $50 \%$ and deadtime of 640 ns. The same DSP carried out the grid-current control and the MPPT. Figure 9 shows the resonant currents. Obviously, the leakage inductances of each phase are not exactly the same. These asymmetries cause small differences in resonant currents amplitudes. However, this has a negligible impact on the SRC3 operation. 


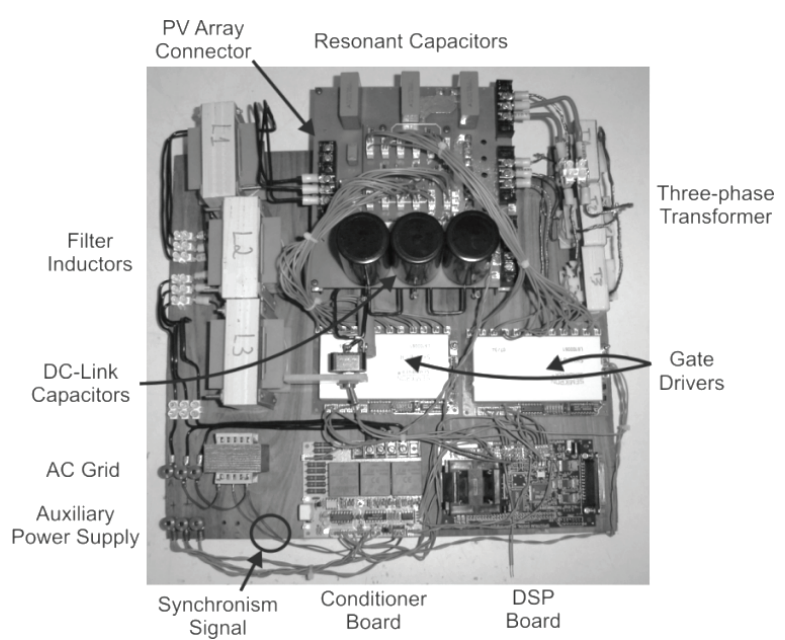

Fig. 8. Laboratory prototype of the modified dual-stage inverter.

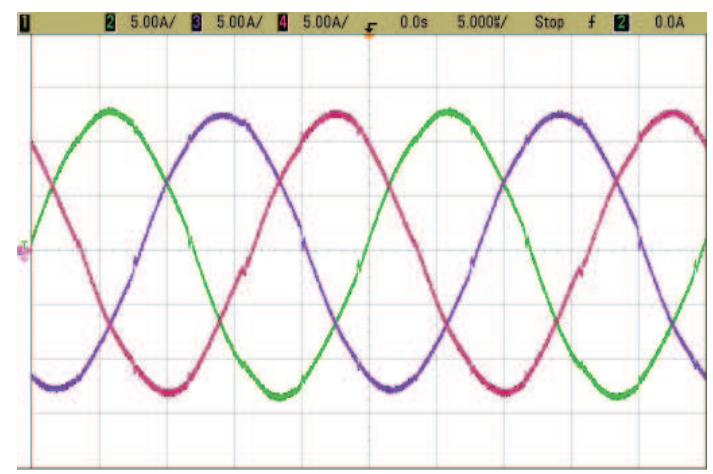

Fig. 9. Resonant currents under nominal conditions.

Figure 10 presents the input and output currents of the DC-DC stage for rating power conditions. These currents have a low ripple and a frequency of six times that of the switching frequency, resulting in a continuous power flux. These features are not common among three-phase DC-DC converters and lead to reduced filter devices. The PV array parallel capacitor is only $680 \mathrm{nF}$. The voltage ripple on it is showed in Figure 11. This ripple was produced by the current Iin. It has a negligible impact above PV array efficiency.

The ZCS commutation is shown in detail in Figure 12. Figure 13 shows the SRC3 efficiency curve.

\section{B. Behavior Matching}

This subsection presents experimental results that validate the Behavior Matching technique.

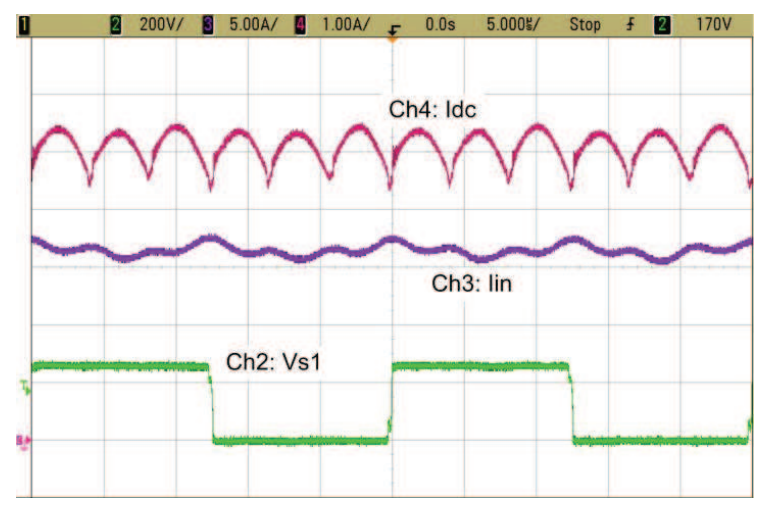

Fig. 10. Input and output currents of the DC-DC stage and collector-emitter voltage, under nominal conditions.

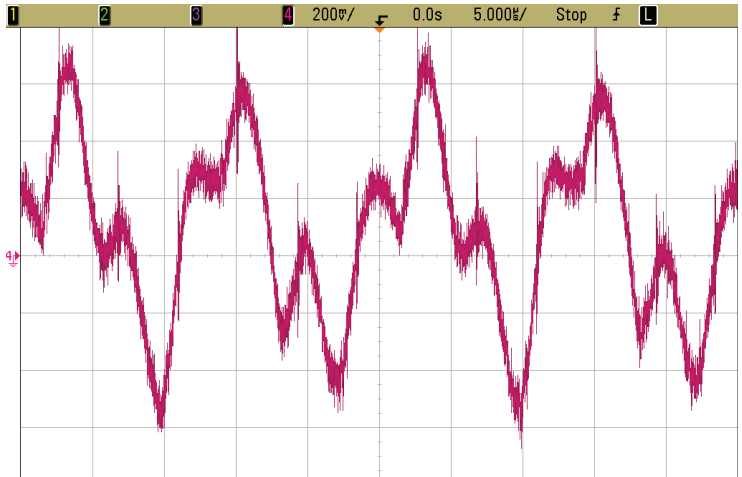

Fig. 11. PV array output voltage for $P_{d c}=500 \mathrm{~W}(200 \mathrm{mV} / \mathrm{div})$.

Figure 14 shows the harmonic spectrum of the voltage across the resonant circuit [14]. The fundamental frequency is $40 \mathrm{kHz}$, i.e., the resonant frequency.

The impact of the voltage harmonic components on the resonant current depends on the resonant circuit quality factor, presented in (14).

$$
Q=2 \cdot \pi \cdot f r \cdot \frac{L d}{R_{\text {loss }}}
$$

The requirement of large impedance for frequencies that are different of the resonant frequency is fulfilled when the quality factor $\mathrm{Q}$ is high. The value of $\mathrm{Q}$ is high in nominal conditions, such as Figure 12.

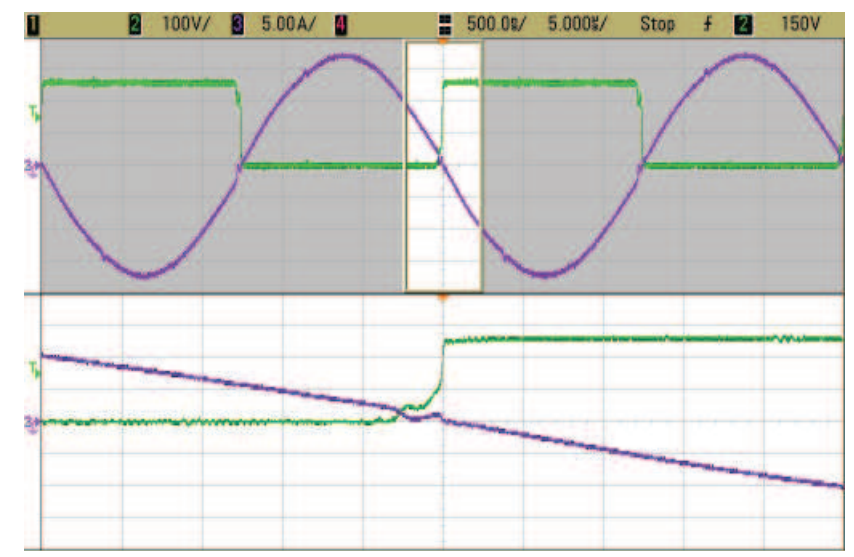

Fig. 12. Resonant current and collector-emitter voltage, under nominal conditions.

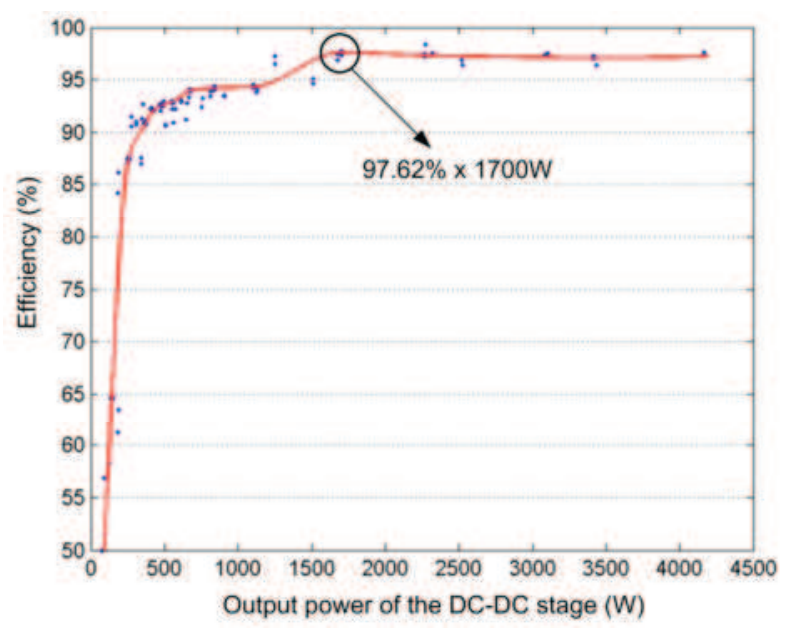

Fig. 13. SRC3 efficiency. 


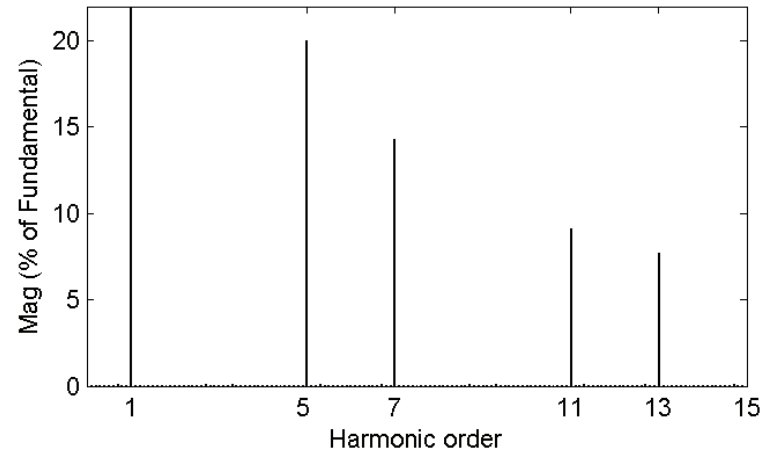

Fig. 14. Harmonic spectrum of the voltage across the resonant circuit.

On the other hand, for low SRC3 output rate power, the $Q$ value is low too. This occurs due increasing of $R_{\text {loss }}$ for output powers below of approximately $1700 \mathrm{~W}$. Figure 13 points to decreasing of efficiency below this power. Larger $L d$ could reduce the power from which $R_{\text {loss }}$ rises. The efficiency would be more flat.

Figure 15 depicts the consequence of the resonant current distortion. For high rated power, the ratio $\operatorname{Iin} / I_{d c}=3.2=n$. For low rated power, the transformer ratio is affected.

In conclusion, when $R_{\text {loss }}$ increases, the equivalent ratio transformer $\left(\operatorname{Iin} / I_{d c}\right)$ also rises.

Reporting to (5), it is verified that Vin could be continuously reduced with the DC-DC stage output power reduction. This effect is depicted in Figure 16.

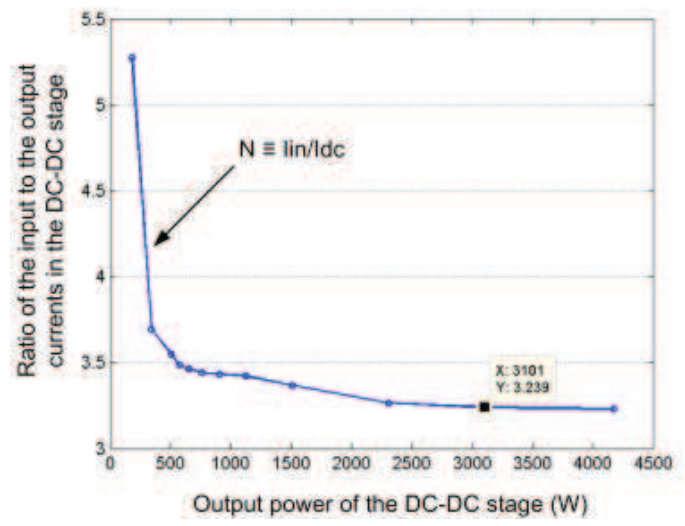

Fig. 15. Input and output currents ratio in the DC-DC stage.

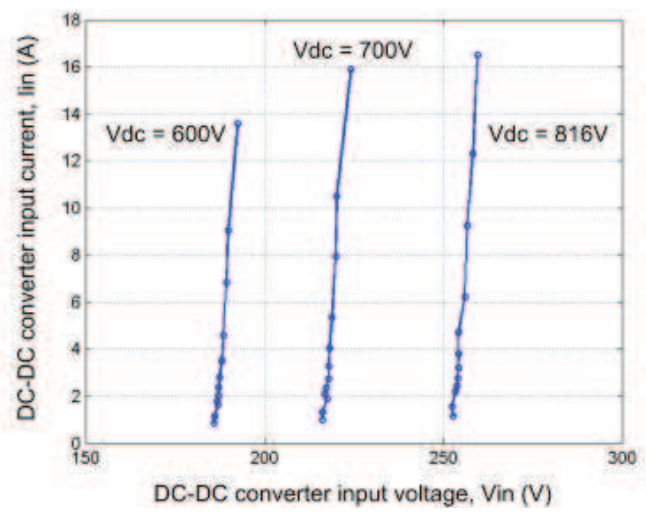

Fig. 16. DC-DC converter input I-V characteristics.
Thus, variations in $R_{\text {loss }}$ are compensated by variations in the equivalent transformer ratio. Moreover, they have the same cause.The inclination of the SRC3 input I-V characteristic, for all $V_{d c}$ operation range, is given by (15), obtained from (2). Figure 16 shows experimentally measured points of SRC3 prototype input I-V characteristic.

$$
\frac{d I n}{d \operatorname{Vin}}=\frac{6}{\pi^{2} \cdot R_{\text {loss }}}=2.3 \frac{\mathrm{A}}{\mathrm{V}}
$$

The DC-DC converter's input characteristic has a propitious behavior to MPPT algorithm. Putting Figure 16 $\left(V_{d c}=816 \mathrm{~V}\right)$ on the PV array I-V characteristic curves, the proximity between the DC-DC converter's input characteristic and the MPP loci can be established, as shown in Figure 17. This collaborates with the MPPT performance for fast changes in atmospheric conditions.

\section{MPPT Performance}

This subsection presents simulation results that reflect the possibility to perform the MPPT using the direct axis current $\left(I_{d}\right)$.

The mathematical model of a $4 \mathrm{kWp}$ PV array is accurate implemented in the form of a current source controlled by voltage, sensible to two input variables, i.e., temperature and solar irradiation power. This model simulates the physical PV array. The MPOPs shift is an almost horizontal line when the temperature changes [2]. The intersection between the characteristics of the PV array and DC-DC converter can deviates from the MPOP. If $V_{d c}$ is keeping constant, thus Vin stays, approximately, constant too. This implies that Ipv and the power from PV array $\left(\mathrm{P}_{\mathrm{MPPT}}\right)$ will decrease. Figure 18 shows the consequences of cell's temperature changes from $25{ }^{\circ} \mathrm{C}$ to $35^{\circ} \mathrm{C}$. The irradiance is $1 \mathrm{~kW} / \mathrm{m}^{2}$ and the air mass is 1.5 .

In order to solve this problem, the $\mathrm{P} \& \mathrm{O}$ method is put in action in the DC-AC stage, as shown in Figure 19. The P\&O parameters are: $T a=50 \mathrm{~ms}$ and $\Delta V=4 \mathrm{~V}(\Delta V$ is the perturbation magnitude and $T a$ is the sampling interval). Thus, in order to maximize the $I_{d}$ current, each $50 \mathrm{~ms}$ the $V_{d c}$ voltage is perturbed by $4 \mathrm{~V}$ on its magnitude. This perturbation can be added or subtracted of $V_{d c}$.

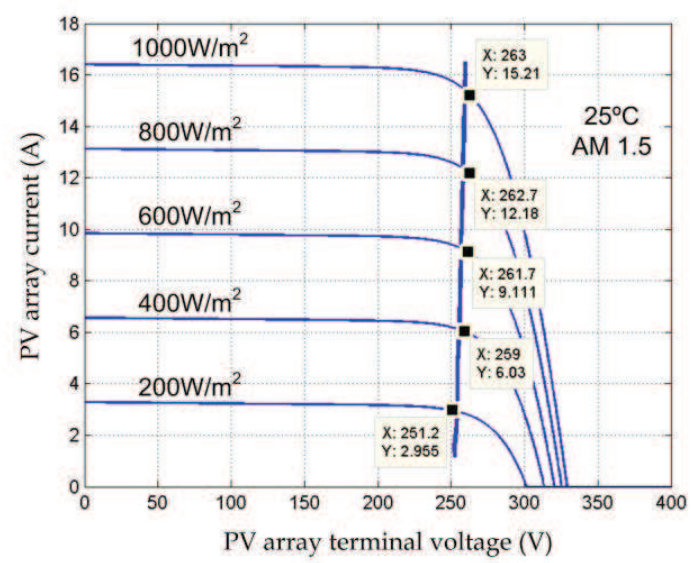

Fig. 17. Crossing between SRC3 and PV array characteristic curves. 


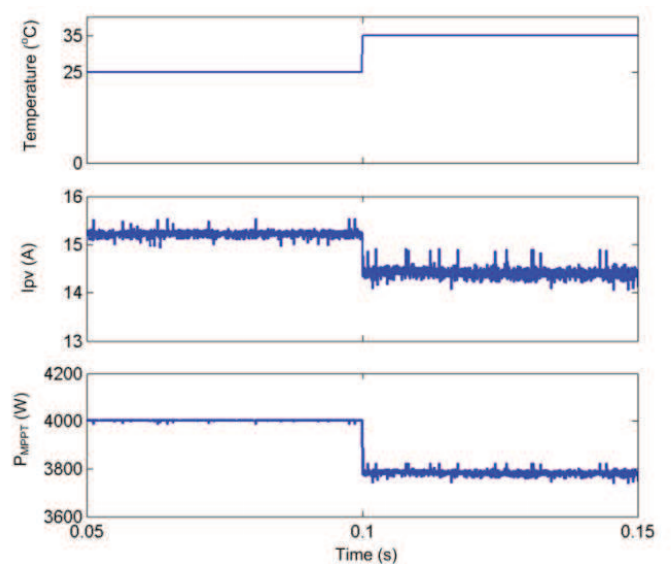

Fig. 18. Temperature variation.
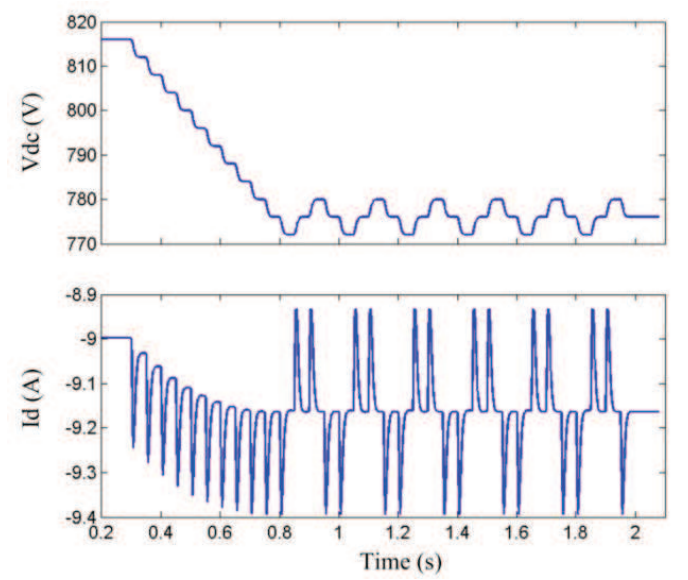

Fig. 19. Execution of the $V_{d c}$ perturbation and $I_{d}$ observation algorithm.

The MPPT algorithm resolves based on the variation of $I_{d}$. The system uses a turns ratio transformer of 1:3.2. Figure 20 shows a zoom on the PV array characteristic curves with the positions (initial, intermediate and final) of the operation point. Figure 21 depicts the trajectory of the PV array output power $\left(\mathrm{P}_{\mathrm{MPPT}}\right)$ as a consequence of the $V_{d c}$ adjustments, drawn from Figure 19.

The relative tracking error, $\varepsilon_{R}$, practically achieves zero in steady state conditions. This occurs due to the shifting of the SRC3 input I-V characteristic close to the MPOP.

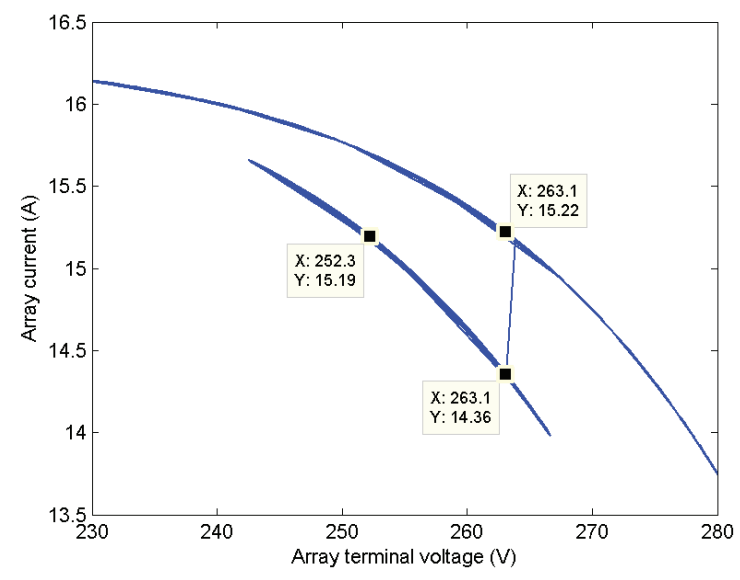

Fig. 20. I-V characteristic curves of the PV array.
D. Performance of the DC-AC Three-Phase Stage

The DC-AC stage is performed by a three-phase PWM voltage source inverter (VSI3) controlled by current, which its power topology is presented in Figure 4. The space vector modulation (SVM) is used in order to minimize the THD of the grid current. Figure 22 depicts the utility voltage and current transferred to the mains power supply, both in phase a, for rated power condition. The THD of the voltage and current are shown in Figures 23 and 24, respectively. An efficiency of $95 \%$ was obtained for the DC-AC stage, and $92 \%$ for the whole system, including the DC-DC stage.
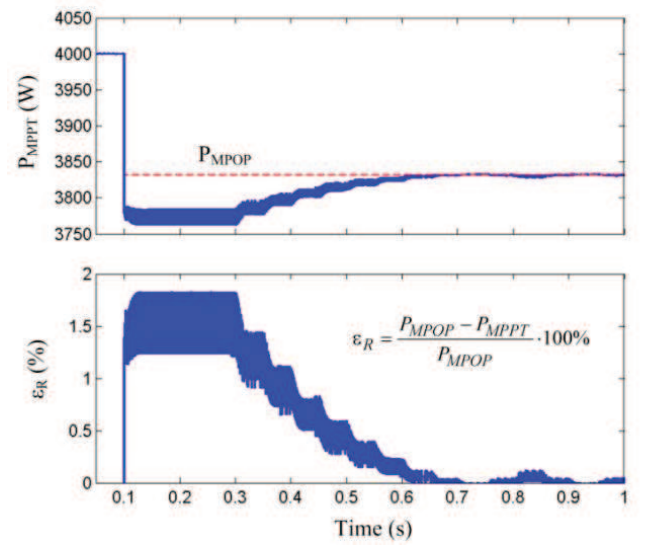

$P_{M P O P}:$ maximum power that the PV array can supply, in the respective conditions of temperature and irradiation;

$P_{M P P T}$ : power obtained from PV array using the proposal MPPT method.

Fig. 21. MPPT performance.

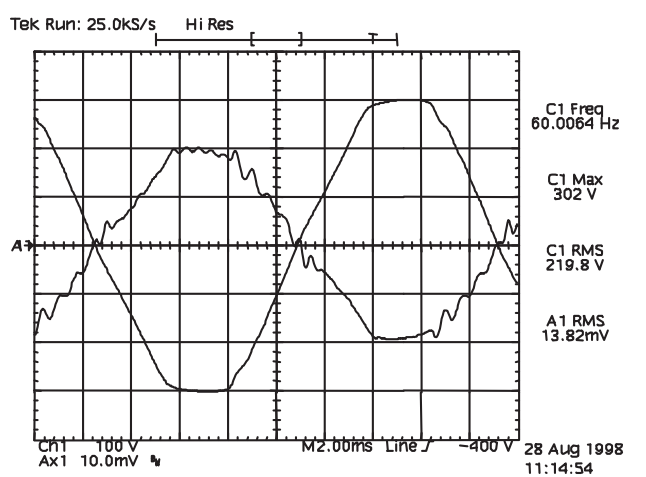

Fig. 22. Voltage and current in the mains power supply (phase a) $100 \mathrm{~V} / \mathrm{div} ; 4 \mathrm{~A} / \mathrm{div} ; 2 \mathrm{~ms} / \mathrm{div}$.

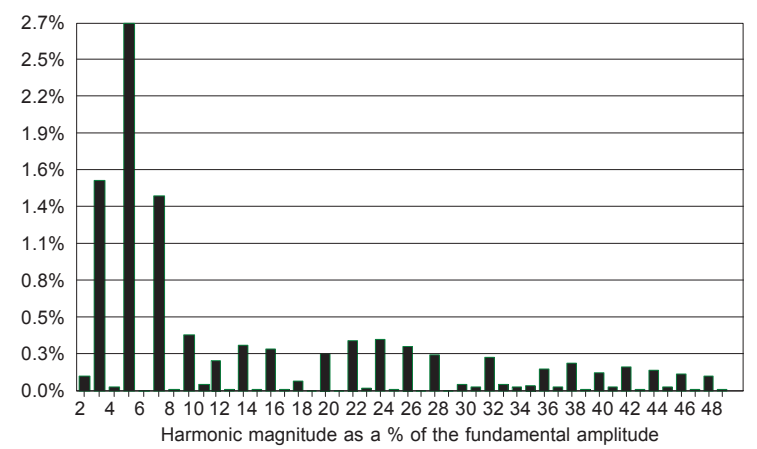

Fig. 23. Voltage harmonic analysis of the mains power supply $\mathrm{THD}=3.69 \%$ 


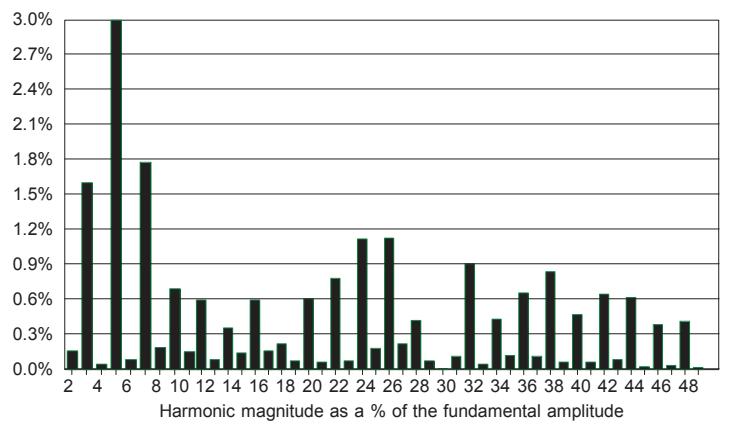

Fig. 24. Current harmonic analysis of the mains power supply $\mathrm{THD}=4.89 \%$, phase angle $=-175^{\circ}$.

Figure 25 presents the performance of the utility voltage and utility current (THD of the current $4.98 \%$, phase angle $=$ $172^{\circ}$ ), with $32 \%$ of the full power delivery to the grid (around $1300 \mathrm{~W}$ ). For this power conditions the whole system efficiency is $90 \%$. Below this power the efficiency decreases drastically.

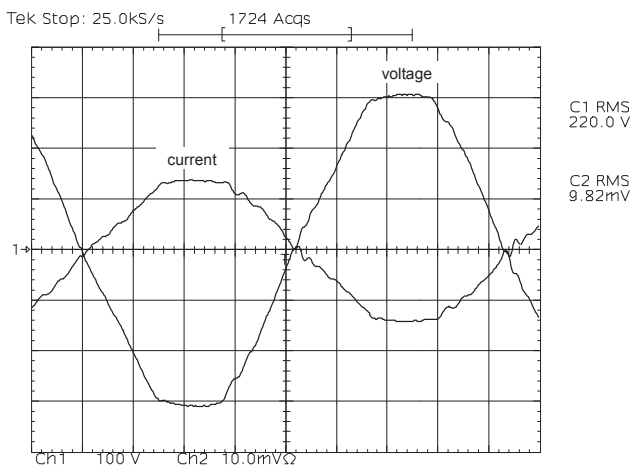

Fig. 25. Utility voltage and utility current with $32 \%$ of the full power - $100 \mathrm{~V} /$ div; $2 \mathrm{~A} /$ div; $2 \mathrm{~ms} /$ div.

\section{CONCLUSION}

In this paper, a modified dual-stage inverter applied to grid-connected photovoltaic systems performed for high power applications has been studied. The modified dualstage inverter contains DC-DC stage and DC-AC stage. Through the Behavior Matching, the DC-DC stage operates with constant frequency and duty cycle and the DC-AC stage becomes responsible for the maximum power point tracking and grid-current control. I-V characteristic of the PV array was reproduced in the output of the DC-DC stage, without any control, which was defined as Behavior Matching. Some sensors could be avoided because the grid-current control apparatus produces the variables needed for the MPPT. In addition, only one digital controller can generate gate pulses for all transistors of the PV system, which results simpler and cheaper topology.

The filter elements size is also reduced due to the low ripple of DC-DC converter input and output current. As a consequence an insignificant capacitor was used on implementation of the PV array parallel filter. Two factors mainly contributed with this advantage: the continuous current flux with low ripple and the barrier formed by the resonant circuit to electrical perturbations on DC link that did not affect the primary side voltage bus. Besides, the Series
Resonant Converter features a robust operation under unbalanced conditions.

The periodic action of the inverter prevents losses and instability, inherent problems of the $\mathrm{P} \& \mathrm{O}$ technique. When the MPOP is found the voltage $V_{d c}$ is clamped, avoiding voltage ripple in the photovoltaic array terminals. Moreover, it can be opted for a small perturbation magnitude, minimizing the steady-state error, since the DC-DC converter is that will response for the fast atmospheric conditions changes. As was seen, it possesses an extremely fast dynamics. Although P\&O method was used others techniques are encouraged.

Finally, the author expects that the efficiency and the implementation simplicity of the whole system are advantages that promote its use.

\section{ACKNOWLEDGEMENT}

The authors would like to thanks the CNPq and FINEP by the financial support.

\section{REFERENCES}

[1] X. Yuan and Y. Zhang, "Status and opportunities of photovoltaic inverters in grid-tied and micro-grid systems," 15th International Photovoltaic Science \& Engineering Conference (PVSEC-15), pp. 226-227, 2005.

[2] M. M. Casaro and D. C. Martins, "Application of the three-phase series resonant converter in a dual-stage inverter operating without specific sensor to perform the MPPT," in Proc. IEEE-IECON'07, 33 ${ }^{\text {rd }}$ Annual Conf. on IEEE Industrial Electronics Society, pp. 1650-1655, 2007.

[3] T. Esram, P. L. Chapman. "Comparison of Photovoltaic Array Maximum Power Point Tracking Techniques," IEEE Transactions on Energy Conversion, vol. 22, no. 2, pp. 439-449, 2007.

[4] M. A. G. de Brito, L. G. Junior, L. P. Sampaio, G. A e Melo and C. A. Canesin, "Main maximum power point tracking strategies intended for photovoltaic," in Pro. COBEP'2011, Brazilian Power Electronics Conference, pp. 524-530, 2011.

[5] R. F. Coelho, F. M. Concer and D. C. Martins, "A simplified analysis of DC-DC converter applied as maximum power point tracker in photovoltaic systems," in Proc. IEEE-PEDG 2010, $2^{\text {nd }}$ IEEE International Symposium on Power Electronics for Distributed Generation Systems, pp. 29-34, 2010.

[6] M. C. Cavalcanti, K. C. Oliveira, G. M. S. Azevedo and F. A. S. Neves. "Comparative Study of Maximum Power Point Tracking Techniques for Photovoltaic Systems," Brazilian Journal of Power Electronics - SOBRAEP, vol.12, pp. 163-171, 2007.

[7] R. F. Coelho, F. M. Concer and D. C. Martins, "Analytical and experimental analysis of DC-DC converters in photovoltaic maximum power point tracking applications," in Proc. IEEE-IECON'2010, $36^{\text {th }}$ Annual Conf. on IEEE Industrial Electronics Society, pp. 2778-2783, Nov. 2010. 
[8] J. M. Carrasco, L. G. Franquelo, J. T. Bialasiewicz, E. Galván, R. C. P. Guisado, M. A. M. Prats, J. I. León and N. Moreno-Alfonso, "Power-electronic systems for the grid integration of renewable energy sources: A Survey," IEEE Transactions on Industrial Electronics, vol. 53, no. 4, pp. 1002-1016, August 2006.

[9] M. M. Casaro and D. C. Martins, "Photovoltaic solar energy electronics processing in grid-connected systems." Brazilian Society Journal of Automatic Control \& Automation, vol. 21, no. 2, pp. 159-172, March/April 2010.

[10]Q. Li and P. Wolfs, "A review of the single phase photovoltaic module integrated converter topologies with three different DC link configurations," IEEE Transactions on Power Electronics, vol. 23, no. 3, pp. 1320-1333, May 2008.

[11]J. P. Lee, B.-D. Min, T. -J. Kim, D.-W. Yoo and J.-Y. Yoo, "A novel topology for photovoltaic DC/DC fullbridge converter with flat efficiency under wide PV module voltage and load range," IEEE Transactions on Industrial Electronics, vol. 55, no. 7, pp. 2655-2663, July 2008.

[12]P. D. Ziogas, A. R. Prasad and S. Manias, "Analysis and design of a three-phase off-line DC/DC converter with high frequency isolation," Proc. IAS'88 Conf., pp. 813820, 1988.

[13]R. W. A. A. De Doncker, D. M. Divan and M. H. Kheraluwala, "A Three-Phase Soft-Switched HighPower-Density dc/dc Converter for High-Power Applications," IEEE Transactions on Industry Applications, vol. 27, no. 1, pp. 63-73, January/February 1991.

[14]J. Jacobs, A. Averberg and R. De Donker, "A Novel Three-Phase DC/DC Converter for High-Power Applications," 35th Annual IEEE Power Electronics Specialists Conference, pp. 1861-1867, 2004.

[15]M. M. Casaro and D. C. Martins, "Application of the three-phase series resonant converter in a dual-stage inverter operating without specific sensor to perform the MPPT," 33rd Annual Conference of the IEEE Industrial Electronics Society, pp. 1650-1655, 2007.

[16]M. M. Casaro and D. C. Martins, "Grid-connected PV system: Introduction to behavior matching," IEEE Power Electronics Specialists Conference, pp. 951-956, 2008.

[17]M. M. Casaro and D. C. Martins, Paths To Sustainable Energy: - Chapter 11: PV Solar Energy Conversion Using the Behavior Matching Technique, Edited by Jatin Nathwani and Artie W. Ng, Published by InTech, pp. 199-210, 2010.

[18]M. M. Casaro and D. C. Martins, "Behavior matching as fundamental feature to obtain a modified dual-stage inverter," IEEE International Symposium on Industrial Electronics - ISIE 2008, pp. 2426-2431, 2008.

[19]M. M. Casaro and D. C. Martins, "Grid-connected PV system using a three-phase modified dual-stage inverter," Brazilian Power Electronics Conference COBEP 2009, pp. 167-173, 2009.

[20]G. M. S. Azevedo, M. C. Cavalcanti, K. C. Oliveira, F. A. S. Neves and Z. D. Lins, "Evaluation of maximum
Power point tracking methods for grid-connected photovoltaic systems," in Proc. IEEE-PESC'08, 39 ${ }^{\text {th }}$ Annual IEEE Power Electronics Specialists Conference, pp. 1456-1462, June 2008.

[21]M. F. Schonardie and D. C. Martins, "Application of the dq0 transformation in the three-phase grid-connected PV systems with active and reactive power control," in Proc. IEEE-ICSET'08, Annual IEEE International Conference on Sustainable Energy Technologies, pp. 18-23, Nov. 2008.

[22]A. R. Prasad, P. D. Ziogas and S. Manias, "A threephase resonant PWM DC-DC converter," 22nd Annual IEEE Power Electronics Specialists Conference, pp. 463-473, 1991.

[23]D. S. Oliveira Jr. and I. Barbi, "A three-phase ZVS PWM DC/DC converter with asymmetrical duty cycle associated with a three-phase version of the hybridge Rectifier," IEEE Transactions on Power Electronics, vol. 20, no. 2, pp. 354-360, March 2005.

[24]M. M. Casaro and D. C. Martins, "Behavior matching technique applied to a three-phase grid-connected PV system," IEEE International Conference on Sustainable Energy Technologies - ICSET 2008, pp. 12-17, 2008.

[25]F. Blaabjerg, R. Teodorescu, Z. Chen and M. Liserre, "Power converters and control of renewable energy systems," Proc. of ICPE'04, pp. I 2-I 20, 2004.

[26]J. Selvaraj and N. A. Rahim, "Multilevel inverter for grid-connected PV system employing digital PI controller," IEEE Transactions on Industrial Electronics, vol. 56, no. 1, pp. 149-158, January 2009.

[27]J. Lopez-Seguel, S. I. Selene, P. Donoso-Garcia, L. F. Morais, P. Cortizo and M. S. Mendes, "Comparison of MPPT approaches in autonomous photovoltaic energy supply system using DSP," in Proc IEEE International Conference on Industrial Technology - IEEE-ICIT 2010, pp. 1149-1154, 2010.

[28]M. M. Casaro and D. C. Martins, "New method of MPPT application for dual-stage inverters," 9th Brazilian Power Electronics Conference, pp. 676-681, 2007.

[29]D. C. Martins and R. Demonti, "Interconnection of a photovoltaic panels array to a single-phase utility line from a static conversion system," in Proc. 31 $1^{\text {st }}$ Annual IEEE Power Electronics Specialists Conference, vol. 3, pp. 1207-1211, 2000.

[30]D. Borgonovo, Modeling and Control of Three-Phase PWM Rectifiers Using the Park Transformation (in Portuguese), Master's Thesis, Federal University of Santa Catarina, Florianópolis, 2001.

\section{BIOGRAPHIES}

Marcio Mendes Casaro was born in Assis, Brazil, in 1972. He received the B.S. degree from Unilins - School of Engineering, Lins, Brazil, and the M.S. and Ph.D. degrees from Federal University of Santa Catarina, Florianópolis, Brazil, all in electrical engineering, in 1994, 1996 and 2009, respectively. He has been working for Federal University of Technology - UTFPR since 1997 as a lecturer of the Department of Electrical Engineering. He is a member of the 
Brazilian Power Electronics Society. His research interests include power electronics converters and their applications.

Lenon Schmitz was born in Blumenau, SC, Brazil, on March 28, 1990. He is in the last semester to receive the B.S. degree in electrical engineering from Federal University of Santa Catarina, Florianópolis, SC, Brazil, and he has been a scientific initiation scholarship student at the Power Electronics Institute since 2010. He was co-author in two scientific papers in the grid-connected systems areas. His interest research field includes dc-dc and dc-ac converters, grid-connected systems and renewable energy.

Carolina Knaesel was born in Blumenau, SC, Brazil, on August 11, 1991. She is in the sixth semester of undergraduate electrical engineering at Federal University of Santa Catarina, Florianópolis, SC, Brazil, and she has been a scientific initiation scholarship student at the Power Electronics Institute since 2012. Her interest research areas include dc-dc and dc-ac converters, grid-connected systems and renewable energy.

Denizar Cruz Martins was born in São Paulo, Brazil, on April 24, 1955. He received the B.S. and M.S. degrees in electrical engineering from Federal University of Santa Catarina, Florianópolis, SC, Brazil, in 1978 and 1981, respectively, and the Ph.D. degree in electrical engineering from the Polytechnic National Institute of Toulouse, Toulouse, France, in 1986. He is currently a Titular Professor in the Department of Electrical Engineering at Federal University of Santa Catarina. . He is a member of the Brazilian Power Electronics Society. His interest research areas include dc-dc and dc-ac converters, high frequency, soft commutation, power factor correction and gridconnected PV systems. 